\title{
Risk factors associated with poor response to immunosuppressive therapy in acquired aplastic anemia: A meta-analysis of retrospective studies
}

\author{
JIA WANG $^{1 *}$, PING SHEN ${ }^{2 *}$, XIANGRU WU ${ }^{1}$ and WENJIE JIN ${ }^{3}$ \\ ${ }^{1}$ Department of Pathology, Xinhua Hospital, Shanghai Jiao Tong University School of Medicine; ${ }^{2}$ Department of \\ Pathology, Shanghai Children's Medical Center Affiliated to Shanghai Jiao Tong University School of \\ Medicine, Shanghai 200092; ${ }^{3}$ Department of Orthopaedics, Shanghai Ninth People's Hospital, \\ Shanghai Jiao Tong University School of Medicine, Shanghai 201999, P.R. China
}

Received July 9, 2019; Accepted January 22, 2020

DOI: $10.3892 /$ etm.2020.8536

\begin{abstract}
Acquired aplastic anemia (AA) is a rare hematological disease characterized by bone marrow hypocellularity and varying degrees of pancytopenia. Immunosuppressive therapy (IST) is currently one of the first-line treatments for AA; however, unresponsiveness remains a major concern. Although previous studies have suggested several common risk factors for unresponsiveness, there are currently no widely accepted predictors. Therefore, a meta-analysis of clinical trials including information on factors associated with unresponsiveness of AA to IST was performed in the present study. The PubMed, Embase and Cochrane Library databases were searched for clinical studies on AA evaluating the association between risk factors and unresponsiveness to IST. After the factors were defined from the selected studies, the association between these factors and unresponsiveness to IST was analyzed using Review Manager software. A total of 10 studies comprising 1,820 cases were included in the present meta-analysis. The following factors were identified as predictors of unresponsiveness: Age ( $\geq 60$ years), sex, absolute neutrophil count, severity of the disease, paroxysmal nocturnal hemoglobinuria clone, human leukocyte antigen (HLA)-DR2 and cytogenetic abnormalities (CAs). Among
\end{abstract}

Correspondence to: Dr Xiangru Wu, Department of Pathology, Xinhua Hospital, Shanghai Jiao Tong University School of Medicine, 1665 Kongjiang Road, Shanghai 200092, P.R. China

E-mail: xiangruwu6@hotmail.com

Dr Wenjie Jin, Department of Orthopaedics, Shanghai Ninth People's Hospital, Shanghai Jiao Tong University School of Medicine, 280 Mohe Road, Shanghai 201999, P.R. China

E-mail: surgeonjin@126.com

*Contributed equally

Key words: aplastic anemia, immunosuppressive therapy, poor response, meta-analysis these factors, only age ( $\geq 60$ years) [odds ratio $(\mathrm{OR})=1.65$ ], HLA-DR2 negativity $(\mathrm{OR}=2.72)$ and $\mathrm{CAs}(\mathrm{OR}=1.93)$ exhibited a statistically significant association with unresponsiveness to IST ( $\mathrm{P}=0.006, \mathrm{P}=0.04$ and $\mathrm{P}=0.01$, respectively). In conclusion, the present meta-analysis revealed that age $\geq 60$ years, HLA-DR2 negativity and CAs are risk factors for unresponsiveness to IST. This result may enable clinicians to select an effective therapeutic scheme for patients with AA and even provide novel clues to the pathogenesis of AA.

\section{Introduction}

Acquired aplastic anemia (AA) is a rare hematological disease characterized by bone marrow hypocellularity and varying degrees of pancytopenia (1). Although etiological studies have demonstrated that drugs (e.g. chloramphenicol), toxic chemicals (e.g. benzene, pesticides), viruses (e.g. hepatitis virus), autoimmune diseases (e.g. lupus erythematosus) and even pregnancy are associated with AA, the pathogenesis of this disease remains largely elusive (1). The final common sign of bone marrow failure is fatty replacement and a marked decrease in the number of marrow $\mathrm{CD} 34^{+}$cells (1); however, the underlying mechanism has remained elusive. In the majority of cases, autoreactive cytotoxic T-lymphocytes cause this disease by suppressing or destroying marrow CD $34^{+}$cells. However, the shorter telomeres of patients with AA and the approximately three-fold increase in the incidence of AA in certain parts of China indicate that other factors may also contribute to the pathogenesis of AA $(1,2)$.

Although AA is non-malignant, it is a life-threatening condition. Prior to the development of allogeneic hematopoietic stem cell transplantation (allo-HSCT) and immunosuppressive therapy (IST), half of the patients with AA did not survive for >4-6 months (3). Allo-HSCT is generally considered as the first-line treatment for young patients who may have a human leukocyte antigen (HLA)-identical sibling donor $(1,4,5)$. Compared with allo-HSCT, IST is used more frequently, particularly for older patients, and in countries and areas where optimal donors may not be available. Unfortunately, $30-40 \%$ of patients with AA respond poorly to IST, although 
the IST regimen has become the standard of care (6). To the best of our knowledge, universally accepted predictors of unresponsiveness to IST have yet to be identified. Therefore, the present meta-analysis was performed to assess several potential predictors of IST unresponsiveness in patients with AA. The results may be helpful in establishing an appropriate therapeutic plan, improving IST efficacy and even providing novel insight into the pathogenesis of AA.

\section{Materials and methods}

Data sources and searches. The PubMed (January 1980 to December 2017), EMbase (January 1980 to December 2017) and Cochrane (January 1980 to December 2017) databases were searched by utilizing the following search terms: ('Immunosuppressive therapy' or 'immunosuppressive treatment') and ('aplastic anemia', 'aplastic anemia' or 'bone marrow failure'). The references of all studies and reviews retrieved were manually scanned to identify additional studies. The language was limited to English.

Study selection. The studies were first screened based on the title and abstract. The full text was then retrieved for further assessment by two authors (WJ and SP). Eligible studies were independently selected by two authors (WJ and SP) according to the following inclusion criteria: a) Clinical trials, prospective studies or retrospective case-control studies; b) diagnostic criteria for severity of AA as determined by the Camitta criteria (Supplemental Table SII) (7); c) anti-thymocyte globulin (ATG) and cyclosporine A (CsA)-based IST regimens; d) response to IST determined using the Bacigalupo criteria (Supplemental Table SIII) (8) and evaluation after a six-month treatment; e) available odds ratios (ORs) and 95\% confidence intervals (CIs) of factors affecting no response to IST; f) reported in English.

Data extraction and quality assessment. Two investigators (WJ and SP) independently extracted the data from all eligible studies. Any disagreements were resolved through discussion with senior investigators (JW and XW). The author name, year of publication, journal and country, as well as the number, age and severity of the cases were recorded. Factors associated with unresponsiveness were retrieved from all eligible studies (Table I). The authors were contacted to request any missing information when necessary.

All eligible studies were independently assessed by two investigators (WJ and SP) according to the Newcastle-Ottawa Scale (NOS) (9) (Supplemental Table SI). The NOS scores ranged between 0 (worst) and 9 (best). Scores of 6 to 9 were rated as being of 'high quality', whereas scores of 0-5 were considered to be of 'poor quality'. Disagreements were resolved as described in the data extraction section.

Definition of assessment factors. The factors were selected for assessment according to the following criteria: a) Available ORs of factors affecting no response to IST and 95\% CI; b) at least two studies including those data.

Data synthesis and analysis. Data were analyzed using Review Manager software (version for Windows; the Cochrane Collaboration). The heterogeneity of included studies was assessed using the $\chi^{2}$-test $(\mathrm{P}<0.10)$ and calculation of the $\mathrm{I}^{2}$ statistic. The fixed-effects model was applied, but when statistically significant heterogeneity was detected $(\mathrm{P}<0.10$ or $\mathrm{I}^{2}>50 \%$ ), the random-effects model was adopted. The results were expressed as ORs with 95\% CI and were presented in forest plots. ORs were used to assess the extent of the association of the factors with poor response of the patients with AA to IST. Differences were considered statistically significant if $\mathrm{P} \leq 0.05$ (two-tailed). Publication bias was assessed using Begg's funnel plots.

\section{Results}

Studies and factors included. Following the search strategy, 3,499 studies were identified, 10 of which were ultimately included in the present meta-analysis (Fig. 1). The characteristics of the studies (10-19) included are summarized in Table I. All of the studies were retrospective and their publication date range was between 1997 and 2011; a total of 1,820 cases in various countries and involving multiple ethnicities were reported, most of which were idiopathic. The mean NOS score was 6.9 (range, 6-7, Table SI), indicating that the quality of the meta-analysis was acceptable. Although the present meta-analysis included the full spectrum of AA (Table I), 4 studies including 469 patients only reported on severe AAb $(12,13,16,18)$ and 2 including 316 patients did not include any data on the severity distribution of the cases $(10,11)$. With regard to the age range of the patients in these studies (10-19, Table I), 5 studies including 795 patients focused on mixed-age groups $(10,14,15,17,18)$, 1 including 316 patients on adult patients( $\geq 18$ years) (16), 2 including 329 patients on pediatric patients $(<18$ years) $(13,19)$, 1 of 99 patients on mixed-age or adult cases (12) and 1 study of 281 patients did not provide the age of the subjects (11).

In the studies included, 7 factors were identified for analysis: Age ( $\geq 60$ years), sex, absolute neutrophil count (ANC), severity of the disease, paroxysmal nocturnal hemoglobinuria (PNH) clone, HLA-DR2 and cytogenetic abnormalities (CAs) (Table I). Although these factors were not included in each study, it was possible to analyze them by combining the data of at least 2 studies from which the ORs were able to be calculated. As a higher age was indicated to be a factor predicting unresponsiveness to IST in previous studies and there is a peak in incidence between the ages of 65 and 69 years $(16,20,21)$, age ( $\geq 60$ years) was included as a factor.

\section{Meta-analysis results for factors included}

Age ( $\geq 60$ years). Two studies $(16,17)$ including 640 patients were reported. Due to the lack of significant heterogeneity among the included studies $\left(\mathrm{P}=0.74, \mathrm{I}^{2}=0 \%\right)$, the fixed-effects model was selected. The total OR $(95 \% \mathrm{CI})$ was $1.65(1.16,2.38)$. The results of the meta-analysis indicated a statistically significant association between age ( $\geq 60$ years) and unresponsiveness to IST ( $\mathrm{P}=0.006$; Fig. 2).

Sex. Four studies $(10,15,17,19)$ including 696 patients were reported. Due to the significant heterogeneity among the included studies $\left(\mathrm{P}=0.04, \mathrm{I}^{2}=64 \%\right)$, the random-effects model was selected. The total OR $(95 \% \mathrm{CI})$ was $0.97(0.48,1.98)$. The results of the meta-analysis did not indicate any statistically significant association between sex and unresponsiveness to IST ( $\mathrm{P}=0.94$; Fig. 3). 


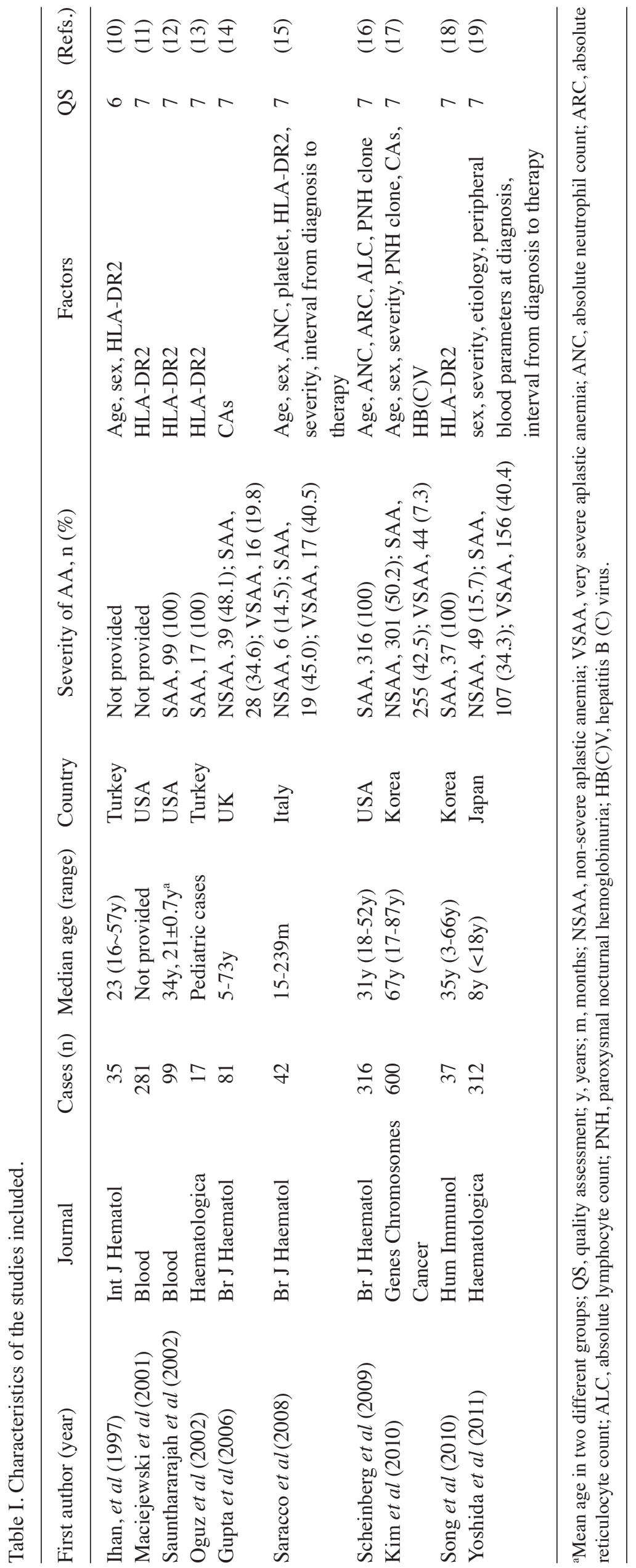




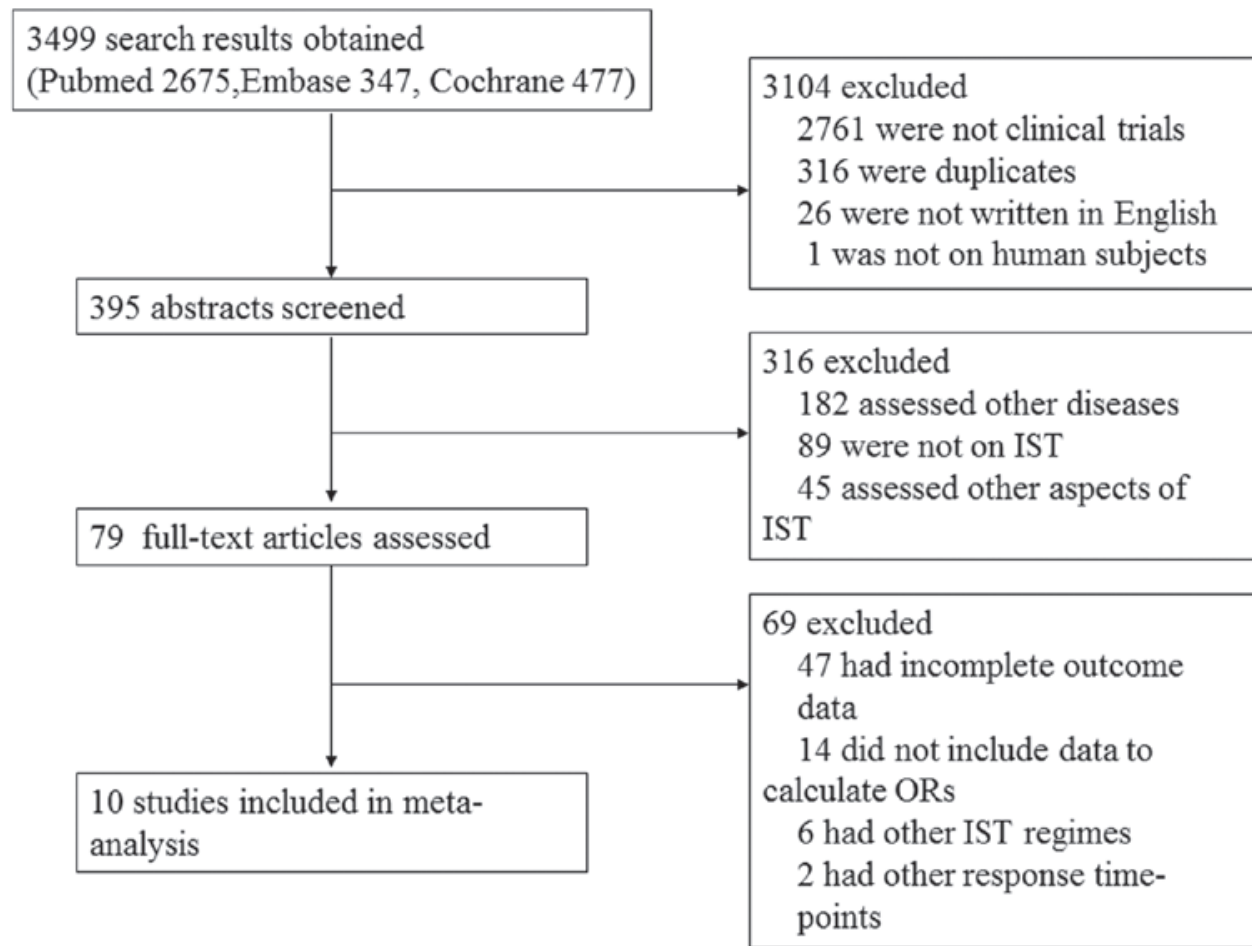

Figure 1. Flow chart depicting the selection process of studies for the present meta-analysis. OR, odds ratio; IST, immunosuppressive therapy.

\begin{tabular}{|c|c|c|c|c|c|c|c|c|c|}
\hline Study or subgroup & \multicolumn{2}{|c|}{ Age $\geq 60 y$} & \multicolumn{2}{|c|}{ Age $<60 y$} & Weight & Odds ratio & \multicolumn{2}{|c|}{$\begin{array}{c}\text { Odds ratio } \\
\mathrm{M}-\mathrm{H} \text {, Fixed, } 95 \% \mathrm{Cl}\end{array}$} & \\
\hline Scheinberg, 2009 & 24 & 51 & 98 & 265 & $35.7 \%$ & $1.51[0.83,2.77]$ & & & \\
\hline Kim, 2010 & 86 & 153 & 73 & 171 & $64.3 \%$ & $1.72[1.11,2.98]$ & & & \\
\hline Total $(95 \% \mathrm{Cl})$ & & 204 & & 436 & $100 \%$ & $1.65[1.16,2.38]$ & & & \\
\hline Total events & 110 & & 171 & & & & & & \\
\hline \multicolumn{6}{|c|}{ Heterogeneity: $\chi^{2}=0.11, d f=1(P=0.74) ;\left.\right|^{2}=0 \%$} & 0.01 & 0.1 & 110 & \\
\hline \multicolumn{6}{|c|}{ Test for overall effect: $Z=2.76(P=0.006)$} & & Age $\geq 60 y$ & Age $<60 y$ & \\
\hline
\end{tabular}

Figure 2. Forest plots of poor response to immunosuppressive therapy according to age. M-H, Mantel-Haentzel; df, degrees of freedom; y, years.

$A N C$. Two studies $(15,16)$ including 354 patients were reported. Due to the significant heterogeneity among the included studies $\left(\mathrm{P}=0.02, \mathrm{I}^{2}=81 \%\right)$, the random-effects model was selected. The total OR $(95 \% \mathrm{CI})$ was $0.67(0.05,8.74)$. The results of the meta-analysis did not indicate a statistically significant association between ANC and unresponsiveness to IST ( $\mathrm{P}=0.76$; Fig. 4).

Severity of disease. Two studies $(17,19)$ including 636 patients were reported. Due to the significant heterogeneity among the included studies $\left(\mathrm{P}=0.09, \mathrm{I}^{2}=65 \%\right)$, the random-effects model was selected. The total OR $(95 \% \mathrm{CI})$ was $1.00(0.53,1.87)$. The results of the meta-analysis did not indicate any statistically significant association between the severity of the disease and unresponsiveness to IST ( $\mathrm{P}=0.99$; Fig. 5).

PNH clone. Two studies $(16,17)$ including 444 patients were reported. Due to the significant heterogeneity among the included studies ( $\left.\mathrm{P}=0.007, \mathrm{I}^{2}=86 \%\right)$, the random-effects model was selected. The total OR $(95 \% \mathrm{CI})$ was $2.85(0.31,25.77)$. The results of the meta-analysis did not indicate any statistically significant association between $\mathrm{PNH}$ clone and unresponsiveness to IST ( $\mathrm{P}=0.35$; Fig. 6 ).

HLA-DR2 6 studies $(10-13,15,18)$ including 486 patients were reported. Due to the significant heterogeneity among the included studies $\left(\mathrm{P}=0.006, \mathrm{I}^{2}=70 \%\right)$, the random-effects model was selected. The total OR $(95 \% \mathrm{CI})$ was $2.72(1.06,7.00)$. The results of the meta-analysis indicated a statistically significant association between HLA-DR2 negative status and unresponsiveness to IST ( $\mathrm{P}=0.04$; Fig. 7).

CAs. Two studies $(14,17)$ including 405 patients were reported. Due to the lack of significant heterogeneity among the included studies $\left(\mathrm{P}=0.52, \mathrm{I}^{2}=0 \%\right)$, the fixed-effects model was selected. The total OR $(95 \% \mathrm{CI})$ was $2.93(1.24,6.95)$. The results of the meta-analysis indicated a statistically significant association between CAs and unresponsiveness to IST ( $\mathrm{P}=0.01$; Fig. 8).

Publication bias. As indicated by the funnel plots (Fig. 9), the studies providing age ( $\geq 60$ years), disease severity and CAs analysis were inside the $95 \%$ CIs, with an even distribution 


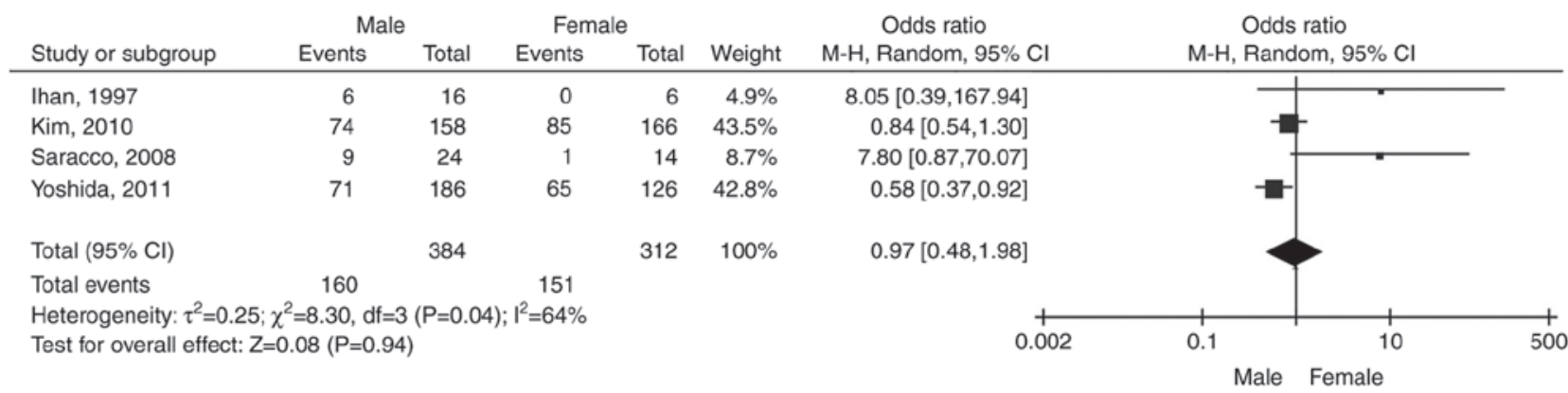

Figure 3. Forest plots of poor response to immunosuppressive therapy according to gender. M-H, Mantel-Haentzel; df, degrees of freedom.

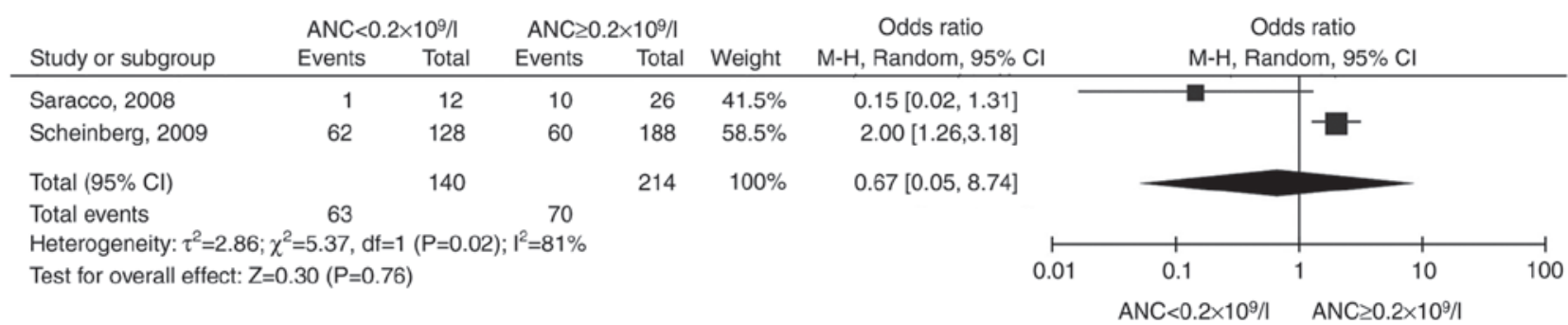

Figure 4. Forest plots of poor response to immunosuppressive therapy according to ANC. M-H, Mantel-Haentzel; df, degrees of freedom; ANC, absolute neutrophil count.

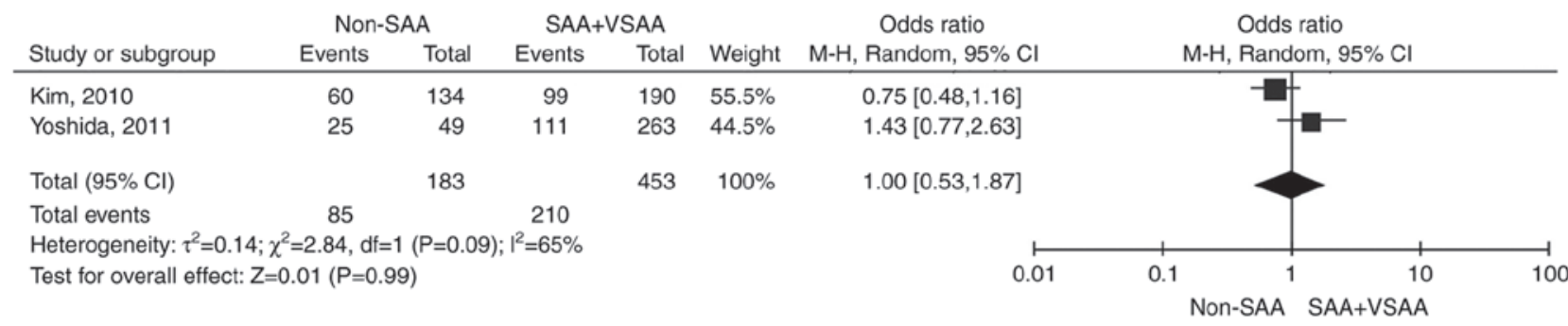

Figure 5. Forest plots of poor response to immunosuppressive therapy according to the severity of the disease. M-H, Mantel-Haentzel; df, degrees of freedom; VSAA, very severe aplastic anemia.

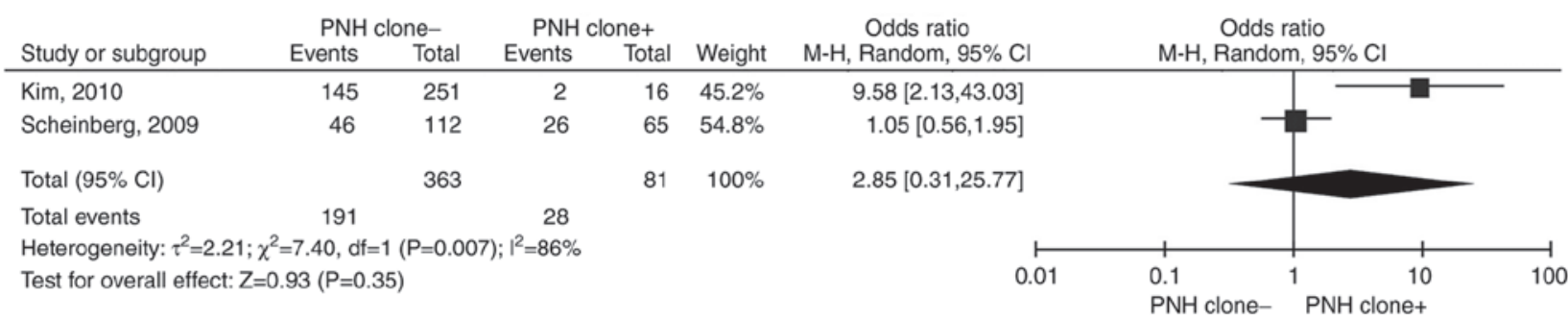

Figure 6. Forest plots of poor response to immunosuppressive therapy according to PNH clone. M-H, Mantel-Haentzel; df, degrees of freedom; PNH, paroxysmal nocturnal hemoglobinuria.

around the vertical symmetry, which indicates that there was no publication bias. However, the other factors were associated with publication bias, with asymmetrical funnel plots (Fig. S1).

\section{Discussion}

AA is a clinical manifestation of bone marrow failure, wherein the hematopoietic stem and precursor cells are nearly absent and are replaced by fat. Accordingly, the varying degrees of decrease in the number of peripheral blood cells result in anemia, infection and bleeding $(1,22)$. HSCT and IST have become the first-line treatments for AA and the 5-year survival rates are similar for patients receiving those therapies $(1,22)$. However, allo-HSCT is limited by age, requirement for a suitably matched sibling donor and post-transplantation complications. Thus, IST is the modality most widely used in AA patients in several countries and geographical areas $(1,22)$. Although IST is one of the most effective treatments for AA, 


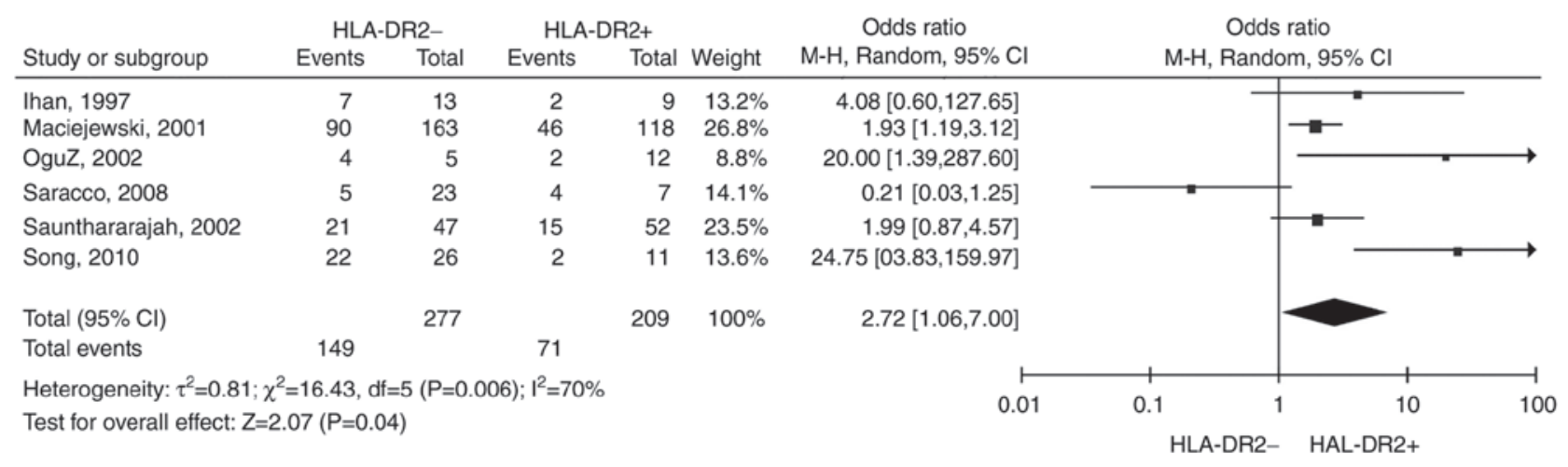

Figure 7. Forest plots of poor response to immunosuppressive therapy according to HLA-DR2. M-H, Mantel-Haentzel; df, degrees of freedom; HLA, human leukocyte antigen.

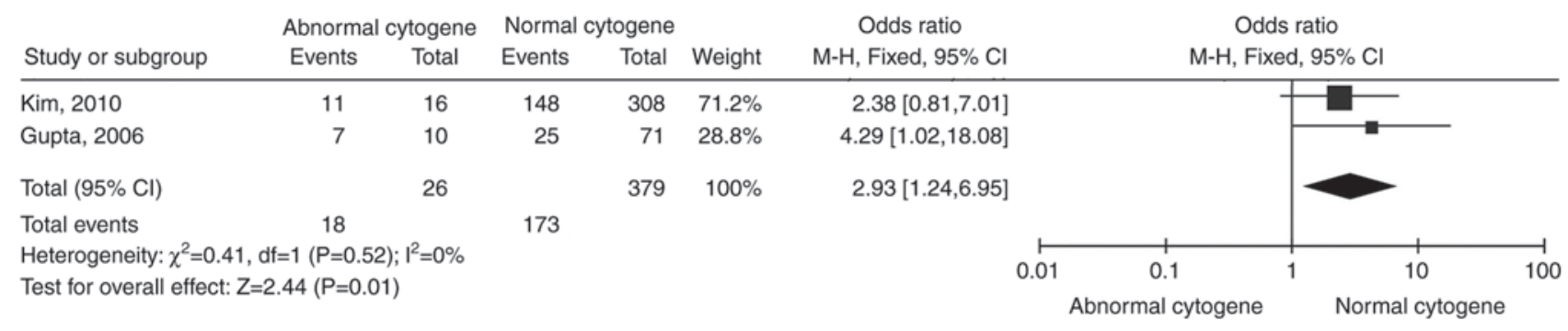

Figure 8. Forest plots of poor response to immunosuppressive therapy according to CAs. M-H, Mantel-Haentzel; df, degrees of freedom; CA, cytogenetic abnormalities.
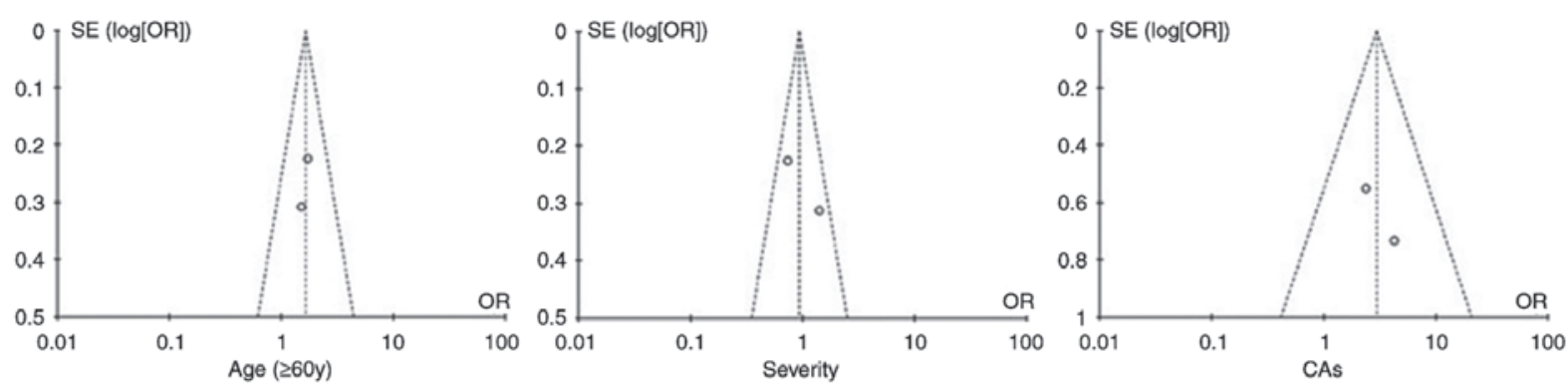

Figure 9. Funnel plots for the assessment of publication bias for the factors of age, severity and CAs. SE, standard error; OR, odds ratio; CAs, cytogenetic abnormalities; y, years.

it is associated with several problems, including unresponsiveness, relapse and malignant transformation $(1,22)$. Several common risk factors associated with unresponsiveness have been reported by previous studies in different populations and areas $(1,10-19,22)$. However, widely accepted predictors of AA have yet to be identified. To the best of our knowledge, the present study was the first meta-analysis of risk factors associated with unresponsiveness to IST in AA. A total of 3 factors, namely age, HLA-DR2 negativity and CAs, were revealed to be statistically significantly associated with unresponsiveness of AA to IST, whereas sex, ANC, disease severity and PNH clone did not exhibit such an association.

Among the three risk factors, old age is most widely recognized. Several studies from different countries and areas have reported that old age is a major prognostic indicator of poor response to IST in AA $(20,23)$. Age is also associated with the incidence of AA (1), with two incidence peaks observed between 15 and 25 years, as well as between 65 and 69 years (1). However, old age is usually negatively associated with the incidence of autoimmune diseases $(21,24)$. In addition, anemia in old patients has the unique characteristics of clinical presentation and prognosis $(25,26)$. These results suggest that anemia in old patients may have a distinct pathogenesis. Certain studies consider that the high incidence and specific presentation of older patients with AA may be linked to telomere length and hematopoietic stem cell number $(2,4)$. However, these previous studies lack convincing evidence and even contradict one another. For instance, numerous studies pointed out that short telomere length may favor the development of AA $(2,4,27,28)$, but older patients with AA do not have a shorter telomere length compared with healthy older subjects (26). Therefore, old patients with AA should be more thoroughly investigated, particularly regarding the pathogenesis of this disease, in order to improve its treatment. 
Similar to age, HLA-DR2 was indicated to be associated with response to IST in previous studies $(10,11,13,15,18)$. In general, patients with HLA-DR2 exhibit a good response to CsA or the combined protocol of CsA + ATG/ALG, but not to ATG/ALG alone. The mechanism underlying their association remains elusive, but the fact that HLA-DR2 is highly expressed in patients with AA and is associated with a good response to IST suggests a key role for HLA-DR2 in AA. It was previously hypothesized that HLA-DR2, which is frequently over-represented in autoimmune diseases, including anti-glomerular basement membrane disease (29) and multiple sclerosis (30), may be a predisposing factor for the immune process of autoimmune diseases, partly as certain HLA haplocytes are not only susceptible to present foreign/self-antigen-derived pathogenic peptides, but are also involved in the formation of autoantigens $(13,29,30)$. In addition, HLA-DR 2 is associated with a decrease in the production of tumor necrosis factor (TNF)- $\alpha(31,32)$. However, TNF- $\alpha$ release increases following activation of interferon (IFN) $-\gamma$ (32). Furthermore, the TNF- $\alpha$ and IFN- $\gamma$ cytokines have an important role in the depletion of bone marrow $\mathrm{CD} 4^{+}$cells in AA (1). Therefore, HLA-DR2 may be involved in the formation of AA through an autoimmune mechanism to a certain extent, whereas HLA-DR2-negative patients with AA may harbor mechanisms other than autoimmunity. This condition is associated with a poor response to IST.

Compared with the former factors, there are certain issues regarding the association between CAs and response to IST in AA. In certain institutions, AA with an abnormal karyotype at the time of diagnosis is considered as myelodysplastic syndrome (33); however, the incidence of CAs at initial diagnosis is approximately $4-15 \%(17,19,34)$, which is not accompanied by morphological changes (17,19,34-39). The mechanism and function of CAs in AA have remained to be fully elucidated due to the scarcity of uniform, systematic and large-scale studies. Based on previous studies, trisomy 8 , trisomy 6 and monosomy 7 are the most common CAs among patients with AA (17,19,34-39). Trisomy 8 and trisomy 6 are frequently present at the time of diagnosis, whereas monosomy 7 almost always develops after treatment (17,19,34-39). Studies on various ethnic groups and geographical areas report that trisomy 8 responds well to IST $(17,19,33,39)$, whereas the opposite was observed for trisomy 6 and monosomy $7(17,19,33,36,39)$, with trisomy 6 reported to be 'the sole predictable marker for IST unresponsiveness' (34). The CAs of AA are not constant over the course of the disease and are transiently present in certain cases (38-40). The different clinical courses of CAs may be associated with their different biology after development, including Fas expression, sensitivity to external stimuli and gene expression profiles, although all of them are considered to initially result from genome instability under immune pressure (41-46). Although the CAs of AA occur at random and are secondary cytogenetic events, the fact that an individual CA is always associated with a specific clinical presentation, along with the multifactorial pathogenesis of AA, cannot exclude the possible involvement of the initial CAs in $\mathrm{CD} 34^{+}$cell depletion $(41,42)$. For instance, trisomy 6 , one of the most common CAs in AA and a predictor of poor response to IST, was characterized by hypoplastic bone marrow in most studies and was observed in early hematopoietic progenitor cells $(10,46,47)$, suggesting that trisomy 6 may be an intrinsic factor causing bone marrow hypoplasia. These results suggest different molecular mechanisms of action and different behavior of these CAs in AA; therefore, further studies should assess individual CAs, rather than CAs as a group.

There were several limitations to this meta-analysis. First, the factors including sex, ANC, PNH clone and HLA-DR2 are associated with publication bias and the quality of included studies are only 6-7 out of 10 on NOS score although three databases were searched. Furthermore, all of the studies included are clinical trials, wherein the deficiencies may be magnified through meta-analysis. In addition, in three of the selected studies, although the source of the patients was different, they were from the same area; thus, the same patients may have been included in more than one study, which may overemphasize the results. However, without more details, it is difficult to determine whether this magnification exists and to what extent. Furthermore, the quality of original data from the studies included cannot be improved by the present meta-analysis. In addition, each factor was analyzed using data from different studies. Using the same studies would be ideal for the analysis of these factors; however, due to the scarcity of published studies on response to IST in AA, there were no more than two studies that shared more than two factors. Finally, only univariate analysis was performed in the present meta-analysis, which may compromise the accuracy of the conclusions. This limitation is attributed to the fact that the analysis results were obtained from different sources. However, the intention was not to reach a definitive conclusion, but rather to detect risk factors of AA unresponsiveness to IST for future research.

In conclusion, the present study demonstrated that age ( $\geq 60$ years), HLA-DR2 negativity and CAs are risk factors of unresponsiveness to IST. This result may be helpful for establishing a treatment guideline for AA. Furthermore, this result may even provide novel clues to the pathogenesis of AA. Some studies suggest that in addition to an abnormal immune system, other factors including telomere length, HLA or CAs, may trigger or be involved in the development of this disease (48-50), which may lead to diverse patterns of responsiveness to IST. Important future research includes large, multicenter clinical trials and laboratory research, in order to help fully elucidate the pathogenesis of AA.

\section{Acknowledgements}

Not applicable.

\section{Funding}

This study was supported by Xinhua Hospital, Shanghai Jiao Tong University School of Medicine (grant no. XH2049).

\section{Availability of data and materials}

All data generated or analyzed during the present study are included in this published article. 


\section{Authors' contributions}

All authors contributed to the scientific work and therefore share collective responsibility and accountability for the results. WJ and XW conceived and designed the study. JW and PS collected and analyzed the data and interpreted the results; JW and PS drafted the manuscript. All authors have read the manuscript and approved the final manuscript.

\section{Ethics approval and consent to participate}

Not applicable.

\section{Patient consent for publication}

Not applicable.

\section{Competing interests}

The authors declare that they have no competing interests.

\section{References}

1. Kaushansky KWW: Williams hematology. New York: McGraw-Hill Medical xxiii: pp.2439, 2010.

2. Townsley DM, Dumitriu B and Young NS: Bone marrow failure and the telomeropathies. Blood 124: 2775-2783, 2014.

3. Marsh JC: Results of immunosuppression in aplastic anaemia. Acta Haematol 103: 26-32, 2000.

4. Risitano AM: Immunosuppressive therapies in the management of immune-mediated marrow failures in adults: Where we stand and where we are going. Br J Haematol 152: 127-140, 2011.

5. Scheinberg P: Aplastic anemia: Therapeutic updates in immunosuppression and transplantation. Hematology Am Soc Hematol Educ Program 2012: 292-300, 2012.

6. Scheinberg P and Young NS: How I treat acquired aplastic anemia. Blood 120: 1185-1196, 2012.

7. Marsh JC, Ball SE, Cavenagh J, Darbyshire P, Dokal I, Gordon-Smith EC, Keidan J, Laurie A, Martin A, Mercieca J, et al: Guidelines for the diagnosis and management of aplastic anaemia. Br J Haematol 147: 43-70, 2009.

8. Bacigalupo A, Broccia G, Corda G, Arcese W, Carotenuto M, Gallamini A, Locatelli F, Mori PG, Saracco P, Todeschini G, et al: Antilymphocyte globulin, cyclosporin, and granulocyte colony-stimulating factor in patients with acquired severe aplastic anemia (SAA): A pilot study of the EBMT SAA Working Party. Blood 85: 1348-1353, 1995.

9. Margulis AV, Pladevall M, Riera-Guardia N, Varas-Lorenzo C, Hazell L, Berkman ND, Viswanathan M and Perez-Gutthann S: Quality assessment of observational studies in a drug-safety systematic review, comparison of two tools: The NewcastleOttawa Scale and the RTI item bank. Clin Epidemiol 6: 359-368, 2014.

10. Ihan O, Beksaç M, Arslan O, Ozcan M, Koç H, Akan H, Gürman G, Konuk N and Uysal A: HLA DR2: A predictive marker in response to cyclosporine therapy in aplastic anemia. Int J Hematol 66: 291-295, 1997.

11. Maciejewski JP, Follmann D, Nakamura R, Saunthararajah Y, Rivera CE, Simonis T, Brown KE, Barrett JA and Young NS: Increased frequency of HLA-DR2 in patients with paroxysmal nocturnal hemoglobinuria and the $\mathrm{PNH} /$ aplastic anemia syndrome. Blood 98: 3513-3519, 2001.

12. Saunthararajah Y, Nakamura R, Nam JM, Robyn J, Loberiza F, Maciejewski JP, Simonis T, Molldrem J, Young NS and Barrett AJ: HLA-DR15 (DR2) is overrepresented in myelodysplastic syndrome and aplastic anemia and predicts a response to immunosuppression in myelodysplastic syndrome. Blood 100 : 1570-1574, 2002.

13. Oguz FS, Yalman N, Diler AS, Oguz R, Anak S and Dorak MT: HLA-DRB1*15 and pediatric aplastic anemia. Haematologica 87: 772-774, 2002
14. Gupta V, Brooker C, Tooze JA, Yi QL, Sage D, Turner D, Kangasabapathy P and Marsh JC: Clinical relevance of cytogenetic abnormalities at diagnosis of acquired aplastic anaemia in adults. Br J Haematol 134: 95-99, 2006

15. Saracco P, Quarello P, Iori AP, Zecca M, Longoni D, Svahn J, Varotto S, Del Vecchio GC, Dufour C, Ramenghi U, et al: Cyclosporin A response and dependence in children with acquired aplastic anaemia: A multicentre retrospective study with long-term observation follow-up. Br J Haematol 140: 197-205, 2008

16. Scheinberg $\mathrm{P}, \mathrm{Wu} \mathrm{CO}, \mathrm{Nunez} \mathrm{O}$ and Young NS: Predicting response to immunosuppressive therapy and survival in severe aplastic anaemia. Br J Haematol 144: 206-216, 2009.

17. Kim SY, Lee JW, Lee SE, Cho BS, Kim M, Eom KS, Kim YJ, Kim HJ, Lee S, Min CK, et al: The characteristics and clinical outcome of adult patients with aplastic anemia and abnormal cytogenetics at diagnosis. Genes Chromosomes Cancer 49: 844-850, 2010.

18. Song EY, Kang HJ, Shin HY, Ahn HS, Kim I, Yoon SS, Park S, Kim BK and Park MH: Association of human leukocyte antigen class II alleles with response to immunosuppressive therapy in Korean aplastic anemia patients. Hum Immunol 71: 88-92, 2010.

19. Yoshida N, Yagasaki H, Hama A, Takahashi Y, Kosaka Y, Kobayashi R, Yabe H, Kaneko T, Tsuchida M, Ohara A, et al: Predicting response to immunosuppressive therapy in childhood aplastic anemia. Haematologica 96: 771-774, 2011.

20. Marsh JC and Kulasekararaj AG: Management of the refractory aplastic anemia patient: What are the options? Hematology Am Soc Hematol Educ Program 2013: 87-94, 2013.

21. Reddy V, Khan S, Wingard JR and Mehta P: Treatment results in aplastic anemia trials need to be analyzed separately for pediatric and adult populations. Blood 94: 1833-1834, 1999.

22. Shin SH and Lee JW: The optimal immunosuppressive therapy for aplastic anemia. Int J Hematol 97: 564-572, 2013.

23. Locasciulli A, Oneto R, Bacigalupo A, Socié G, Korthof E, Bekassy A, Schrezenmeier H, Passweg J and Führer M; Severe Aplastic Anemia Working Party of the European Blood and MarrowTransplant Group: Outcome of patients with acquired aplastic anemia given first line bone marrow transplantation or immunosuppressive treatment in the last decade: A report from the European Group for Blood and Marrow Transplantation (EBMT). Haematologica 92: 11-18, 2007.

24. Vadasz Z, Haj T, Kessel A and Toubi E: Age-related autoimmunity. BMC Med 11: 94, 2013.

25. Andro M, Le Squere P, Estivin S and Gentric A: Anaemia and cognitive performances in the elderly: A systematic review. Eur J Neurol 20: 1234-1240, 2013.

26. den Elzen WP and Gussekloo J: Anaemia in older persons. Neth J Med 69: 260-267, 2011.

27. Young NS: Pathophysiologic mechanisms in acquired aplastic anemia. Hematology Am Soc Hematol Educ Program: 72-77, 2006.

28. Young NS, Calado RT and Scheinberg P: Current concepts in the pathophysiology and treatment of aplastic anemia. Blood 108: 2509-2519, 2006

29. Nepom GT: Class II antigens and disease susceptibility. Annu Rev Med 46: 17-25, 1995.

30. Haegert DG and Marrosu MG: Genetic susceptibility to multiple sclerosis. Ann Neurol 36 (Suppl 2): S204-S210, 1994.

31. Peces R, Urra JM and de la Torre M: Influence of HLA-DR phenotype on tumor necrosis factor-alpha production in renal-transplant recipients. Nephron 71: 180-183, 1995.

32. Bendtzen K, Morling N, Fomsgaard A, Svenson M, Jakobsen B, Odum N and Svejgaard A: Association between HLA-DR2 and production of tumour necrosis factor alpha and interleukin 1 by mononuclear cells activated by lipopolysaccharide. Scand J Immunol 28: 599-606, 1988.

33. Maciejewski JP, Risitano A, Sloand EM, Nunez O and Young NS: Distinct clinical outcomes for cytogenetic abnormalities evolving from aplastic anemia. Blood 99: 3129-3135, 2002.

34. Ohga S, Ohara A, Hibi S, Kojima S, Bessho F, Tsuchiya S, Ohshima Y, Yoshida N, Kashii Y, Nishimura S, et al: Treatment responses of childhood aplastic anaemia with chromosomal aberrations at diagnosis. Br J Haematol 118: 313-319, 2002.

35. Mikhailova N, Sessarego M, Fugazza G, Caimo A, De Filippi S, van Lint MT, Bregante S, Valeriani A, Mordini N, Lamparelli T, et al: Cytogenetic abnormalities in patients with severe aplastic anemia. Haematologica 81: 418-422, 1996.

36. Kearns WG, Sutton JF, Maciejewski JP, Young NS and Liu JM: Genomic instability in bone marrow failure syndromes. Am J Hematol 76: 220-224, 2004. 
37. Keung YK, Pettenati MJ, Cruz JM, Powell BL, Woodruff RD and Buss DH: Bone marrow cytogenetic abnormalities of aplastic anemia. Am J Hematol 66: 167-171, 2001.

38. Piaggio G, Podestà M, Pitto A, Sessarego M, Figari O, Fugazza G, Benvenuto F, Bruno B, Van Lint MT, Truini M, et al: Coexistence of normal and clonal haemopoiesis in aplastic anaemia patients treated with immunosuppressive therapy. Br J Haematol 107: 505-511, 1999.

39. Geary CG, Harrison CJ, Philpott NJ, Hows JM, Gordon-Smith EC and Marsh JC: Abnormal cytogenetic clones in patients with aplastic anaemia: Response to immunosuppressive therapy. $\mathrm{Br}$ J Haematol 104: 271-274, 1999.

40. Appelbaum FR, Barrall J, Storb R, Ramberg R, Doney K, Sale GE and Thomas ED: Clonal cytogenetic abnormalities in patients with otherwise typical aplastic anemia. Exp Hematol 15: 1134-1139, 1987.

41. Afable MG II, Tiu RV and Maciejewski JP: Clonal evolution in aplastic anemia. Hematology Am Soc Hematol Educ Program 2011: 90-95, 2011.

42. Sloand EM, Kim S, Fuhrer M, Risitano AM, Nakamura R Maciejewski JP, Barrett AJ and Young NS: Fas-mediated apoptosis is important in regulating cell replication and death in trisomy 8 hematopoietic cells but not in cells with other cytogenetic abnormalities. Blood 100: 4427-4432, 2002.

43. Chen G, Zeng W, Miyazato A, Billings E, Maciejewski JP, Kajigaya S, Sloand EM and Young NS: Distinctive gene expression profiles of CD34 cells from patients with myelodysplastic syndrome characterized by specific chromosomal abnormalities. Blood 104: 4210-4218, 2004.

44. Kojima S, Ohara A, Tsuchida M, Kudoh T, Hanada R, Okimoto Y, Kaneko T, Takano T, Ikuta K and Tsukimoto I; Japan Childhood Aplastic Anemia Study Group: Risk factors for evolution of acquired aplastic anemia into myelodysplastic syndrome and acute myeloid leukemia after immunosuppressive therapy in children. Blood 100: 786-790, 2002
45. Sloand EM, Yong AS, Ramkissoon S, Solomou E, Bruno TC, Kim S, Fuhrer M, Kajigaya S, Barrett AJ and Young NS: Granulocyte colony-stimulating factor preferentially stimulates proliferation of monosomy 7 cells bearing the isoform IV receptor. Proc Natl Acad Sci USA 103: 14483-14488, 2006.

46. Mohamed AN, Varterasian ML, Dobin SM, McConnell TS, Wolman SR, Rankin C, Willman CL, Head DR and Slovak ML: Trisomy 6 as a primary karyotypic aberration in hematologic disorders. Cancer Genet Cytogenet 106: 152-155, 1998.

47. Argiropoulos B, Clifford B, Crocker S, Sinclair-Bourque E, McCready E, McGowan-Jordan J, Johnston DL and Padmore R: HLA-DR(negative), CD34(negative) hypergranular acute myeloid leukemia with trisomy 6 and del(5)(q22q33): Case report and review of the literature. J Pediat Hematol Oncol 33: e289-e295, 2011.

48. Boddu PC and Kadia TM: Molecular pathogenesis of acquired aplastic anemia. Eur J Haematol 102: 103-110, 2019.

49. Shallis RM, Ahmad R and Zeidan AM: Aplastic anemia: Etiology, molecular pathogenesis, and emerging concepts. Eur J Haematol 101: 711-720, 2018.

50. Wang L and Liu H: Pathogenesis of aplastic anemia. Hematology 24: 559-566, 2019.

This work is licensed under a Creative Commons Attribution-NonCommercial-NoDerivatives 4.0 International (CC BY-NC-ND 4.0) License. 